the rest of the world as from NW Europe. The first two chapters not only bring together a variety of extremely useful material on their physico-chemical characteristics which is not readily available elsewhere, but also present it in a clear, practical and biologically relevant manner. They will prove particularly informative to biologists lacking a background of physical geography. Chapter 3 gives an account of saltmarsh and shore vegetation which, although necessarily brief, nevertheless mentions mangroves and fungi as well as Salicornia and Spartina; it is followed by classifications of habitats and their faunal components.

The main body of the book deals with the planktonic, benthic and pelagic fauna more or less in taxonomic order, giving particular consideration to the salinity tolerance and other appropriate adaptations of the animals selceted as examples. Species of marine origin preponderate amongst these examples as they do in the habitat itself, but the author devotes a chapter each to animals of freshwater and terrestrial origin and to estuarine birds. This is both gratifying and useful to one who has previously found estuaries mentioned only in works on marine biology. The book closes with a chapter on parasites and epibionts, and a short account of estuarine food webs.

With such a wide field to cover, the over-critical reader is cortain to find omissions in the sections dealing with his own speciality. More could have been said about pollution and, having referred to the spread of Elminius by shipping, fouling and wood-boring problems might also have been touched on. Limnoria and Teredo are not mentioned, nor is there any indication that Mercierella occurs in British as well as African estuaries and can be troublesome there. I should have liked more pictures of the animals; 105 figures in just under 350 text pages seem fewer than they sound when some occupy more than half a page in illustrating a single animal. In some of the more obscure groups the nomenclature is rather erratic, and the systematic approach occasionally causes one to lose sight of the ecology of estuaries as a whole, although for ease of reference there may be much to recommend it. Dr Green gives clear definitions of his technical terms and these are readily found through the very complete single index; his bibliography is equally full, containing well over 500 references. The book will be very useful to workers in the field, whether sixth formers or postgraduates. An undergraduate studying any course with a marine bias should not only be required to read it but ought to enjoy the experience; at such a reasonable price he might well be expected to buy his own copy.

A. Nelison-Smith

\section{ANIMAL HOUSES}

The Design and Function of Laboratory Animal Houses Edited by Ronald Hare and P. N. O'Donoghue. (Laboratory Animal Symposia, No. 1.) Pp. 141. (Laboratory Animals: London, 1968.) 22s. 6d.

This volume shows the increasing interest in the accom. modation of laboratory animals, and should be read by anyone considering designing a new animal house or redesigning an old one. It is very interesting to have the comments from the architects and service engineers. It is perhaps a pity that the discussion was not included, and in general the approach is based on what has been built, rather than what is possible in the future. More emphasis might be placed on time and motion studies on caging and layouts. Among the contributions are ones on the accommodation for primates, radioactive experiments, infected animals and gnotobiotics. Dawson and Hadley suggest a new approach to the ventilation of animal rooms and stress the almost complete lack of data on heat production by laboratory animals. One chapter. considers the importance of designing the unit round the central services, including cage washing and sterilization.

Some of the views are rather personal, and I doubt if there would be general agreement for the suggestion that lights should be left on permanently (page 59).

This volume can be recommended as a general introduction to anyone designing an animal house, but the necessary detailed information is best obtained by visiting an animal unit; this also shows the design in use and the effects of wear and tear.

The authors and editor are to be congratulated on the promptness of publication.

M. C. Lancaster

\section{VOLUME OF REPRINTS}

The Mind

Biological Approaches to Its Functions. Edited by William C. Corning and Martin Balaban. Pp. ix +321 . (Interscience (John Wiley): New York and London, 1968.) $117 s$.

IT is impossible to disagree with a preface which asserts that brain research is a subject of great significance, and that it is currently receiving considerable attention. It is also, however, an area in which knowledge is advancing at such a rate that no purpose is served by reprinting articles first published in 1959 and 1960. This is true even of so seminal a paper as that by Lettvin et al. on the behaviour of single units in the frog visual system. Not only is this widely familiar, thanks to repeated eitations in later work, but it has been made available before in collections of reprinted papers.

The articles which have not appeared previously elsewhere are diverse in content, and it is difficult to see any special reason for their assuciation into a single volume beyond the fact that most are based on a single series of lectures given at Michigan State University. The three by Corning, Schmitt and McConnell do form a natural group. All illustrate only too clearly the tendency to imitate older and better established sciences which has bedevilled psychology. In Hull's day it was physics; today for some psychologists it is molecular biology.

The theories and data discussed appear to be reducible to three possible phenomena. Firstly, increased RNA content following neuronal activity of a type involved in learning may reflect increased protein synthesis needed for structural and chemical changes at synapses and elsewhere. Clearly this is only an extension of the classic structural theory of the engram. The second possibility is that memories are coded into complex molecules, and are transmissible as molecular extracts. No mechanism which would enable such a code to be translated into patterns of neuronal activity is suggested at any point. Thirdly, membrane specificities with, naturally, a molecular basis, may be involved in the establishment of appropriate connexions between neurones during development. It is not clear that this has any relation to engram formation. All three phenomena are confused together to a greater or lesser extent throughout the articles under discussion.

The most interesting article is certainly that of Kilmer et al. on a computer model of the reticular formation. Much of the most interesting material is in the appendices and will no doubt become more accessible when the work is published in extended form. The oddest article, on the other hand, is by Driver, who feels that the adverse treatment of On Aggression (by Lorenz) at the hands of Barnett, Schneirla and others is so unfair (and, apparently, disrespectful) as to indicate a division of ethology into two sciences, only one of which, the Lorenzian, can be considered true ethology. No scientific arguments advanced by either side are discussed, so that I can only comment that, in my opinion, On Aggression was a mis- 